\title{
INDICADORES DE COBERTURA VACINAL PARA CLASSIFICAÇÃO DE RISCO DE DOENÇAS IMUNOPREVENÍVEIS
}

\section{Vacinnation coverage indicators for risk classification of vaccine-preventable diseases Indicadores de cobertura de vacunación para la clasificación de riesgo de enfermedades inmunoprevenibles}

\author{
Aline Beatriz dos Santos Silva (iD \\ Universidade Federal de Pernambuco - UFPE - Recife (PE) - Brasil \\ Ana Catarina de Melo Araújo iD \\ Secretaria Estadual de Saúde de Pernambuco - SES - Recife (PE) - Brasil \\ Michelle Caroline da Silva Santos iD \\ Secretaria Estadual de Saúde de Pernambuco - SES - Recife (PE) - Brasil \\ Maria Sandra Andrade (iD \\ Universidade Estadual de Pernambuco - UPE - Recife (PE) - Brasil \\ Rafael Mota Mendonça (iD \\ Universidade Federal de Pernambuco - UFPE - Recife (PE) - Brasil
}

\section{RESUMO}

Objetivo: Descrever os indicadores de cobertura vacinal e o risco de transmissão de doenças imunopreveníveis. Métodos: Estudo ecológico descritivo, tendo como unidade de análise os municípios da $1^{\text {a }}$ Região de Saúde do estado de Pernambuco. Utilizou-se a metodologia proposta pelo Ministério da Saúde, elaborada no ano de 2016, para classificação de risco de doenças imunopreveníveis, e coletaram-se os dados no Sistema de Informações do Programa Nacional de Imunizações do estado. Descreveram-se as variáveis referentes à situação vacinal das vacinas básicas para os menores de dois anos de idade (cobertura vacinal, taxa de abandono e homogeneidade da cobertura vacinal) e o risco de transmissão de doenças imunopreveníveis a partir da distribuição de frequências absolutas, relativas e médias. Resultados: Dos vinte municípios analisados, $20 \%$ ( $n=4$ ) apresentaram a classificação de risco muito alto, $55 \%(n=11)$ tiveram risco alto, $15 \%(n=3)$ apresentaram risco médio e 10\% ( $n=2)$ classificaram-se com risco muito baixo. As vacinas tetra viral, rotavírus e meningocócica $\mathrm{C}$ apresentaram os menores valores de cobertura na região: $25 \%(n=5)$ dos municípios alcançaram a meta da homogeneidade da cobertura vacinal entre vacinas e $20 \%(n=4)$ dos municípios estão com esse indicador zerado. As vacinas rotavírus, pentavalente e poliomielite apresentaram as maiores taxas de abandono. Conclusão: Nos municípios analisados há um enquadramento nas categorias de risco muito alto e alto, além de baixos indicadores de cobertura vacinal, evidenciando que há uma relação inversamente proporcional entre o risco e os indicadores.

Descritores: Epidemiologia Descritiva; Cobertura Vacinal; Imunização; Risco.

\section{ABSTRACT}

Objective: To describe vaccination coverage indicators and the risk of transmission of vaccine-preventable diseases. Methods: This is a descriptive ecological study whose unit of analysis consists of the municipalities of the $1^{\text {st }}$ Health Region of the state of Pernambuco. The methodology proposed by the Ministry of Health and prepared in 2016 was used to classify the risk of vaccine-preventable diseases and data were collected from the Information System of the National Immunization Program of the State. Variables related to the vaccination status of the basic vaccines for children under two years of age (vaccination coverage, abandonment rate and homogeneity of vaccination coverage) and the risk of vaccine-preventable diseases were described through the distribution of absolute and relative frequencies and means. Results: Of the twenty municipalities analyzed, 20\% ( $n=4)$ were at very high risk, $55 \%(n=11)$ were at high risk, $15 \%(n=3)$ were at intermediate risk and $10 \%(n=2)$ were at very low risk. The Tetra viral, Rotavirus and Meningococcal $C$ vaccines had the lowest coverage values in the region: $25 \%(n=5)$ of the municipalities reached the goal of homogeneity of vaccination coverage between vaccines and $20 \%(n=4)$ of the municipalities scored zero

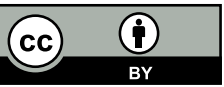


on this indicator. The Rotavirus, Pentavalent and Poliomyelitis vaccines had the highest abandonment rates. Conclusion: The municipalities analyzed fall into the categories of very high and high risk and present low rates of vaccination coverage, thus showing that there is an inversely proportional relationship between risk and indicators.

Descriptors: Epidemiology, Descriptive; Vaccination Coverage; Immunization; Risk.

\section{RESUMEN}

Objetivo: Describir los indicadores de cobertura de vacunación y el riesgo de transmisión de enfermedades inmunoprevenibles. Métodos: Estudio ecológico descriptivo que tiene como la unidad de análisis los municipios de la $1^{a}$ Región de Salud del estado de Pernambuco. Se utilizó la metodología propuesta por el Ministerio de la Salud elaborada en el año de 2016 para la clasificación de riesgo de enfermedades inmunoprevenibles y se recogieron los datos del Sistema de Informaciones del Programa Nacional de vacunas del estado. Se describieron las variables referentes a la situación de vacunación de las vacunas básicas para los que tienen menos de dos años de edad (cobertura de vacunación, tasa de abandono y homogeneidad de la cobertura de vacunación) y el riesgo de transmisión de enfermedades inmunoprevenibles a partir de la distribución de frecuencias absolutas, relativas y medias. Resultados: De los veinte municipios analizados, el $20 \%(n=4)$ presentaron la clasificación de riesgo muy alto, el $55 \%$ $(n=11)$ tuvieron riesgo alto, el 15\% $(n=3)$ presentaron riesgo medio y el 10\% $(n=2)$ se han clasificado de riesgo muy bajo. Las vacunas tetra viral, rotavirus y la antimeningocócica $C$ presentaron los valores más bajos de la cobertura en la región: el $25 \%$ $(n=5)$ de los municipios han alcanzado la meta de la homogeneidad para la cobertura de vacunación entre vacunas y el $20 \%$ $(n=4)$ de los municipios tiene cero para ese indicador. Las vacunas rotavirus, pentavalente y poliomielitis presentaron las más altas tasas de abandono. Conclusión: Hay un encuadramiento de las categorías de riesgo muy alto y alto en los municipios analizados, además de bajos indicadores de cobertura de vacunación con la evidencia de una relación inversamente proporcional entre el riesgo y los indicadores.

Descriptores: Epidemiología Descriptiva; Cobertura de Vacunación; Inmunización; Riesgo.

\section{INTRODUÇÃO}

A vacinação se configura como elemento essencial no direito à saúde, sendo um componente de responsabilidade governamental que, no seu conceito amplo, constitui-se como um dever do Estado brasileiro. Graças à imunização, previne-se cerca de 2,5 milhões de óbitos/ano, evidenciando que as crianças devidamente protegidas tendem a ter um desenvolvimento mais saudável(1).

As práticas de imunização são importantes atividades da atenção básica ofertada pela Estratégia de Saúde da Família, auxiliando, assim, no compartilhamento de compromissos e funcionando como agente promotor de saúde, agindo favoravelmente na qualidade de vida dos indivíduos. Elas trazem à tona a reflexão da potencialidade das atividades de imunização como ferramenta de promoção da saúde, visto que estão intimamente ligadas à melhoria da qualidade de vida ao reforçar o sistema imunológico e atenuar os riscos de adquirir e transmitir doenças transmissíveis. Portanto, o papel dos profissionais de saúde atuantes nessa área é basilar para a garantia de qualidade de vida da população, visto que estes são considerados pela população como a principal e mais confiável fonte de informação(2).

Além disso, a vacinação é uma ferramenta de relação custo-benefício efetiva e eficiente na saúde pública, e seu impacto na saúde coletiva apresenta vários quesitos importantes, como o aumento da expectativa de vida (o advento da vacinação conseguiu atenuar a mortalidade, a qual antes apresentava números expressivos), a erradicação de certas doenças (como a varíola) e a garantia de benefícios sociais e econômicos ${ }^{(3)}$.

No Brasil, em 1973, instituiu-se o Programa Nacional de Imunização (PNI) e, dois anos depois, formalizaram-se suas normas técnicas de funcionamento ${ }^{(4)}$. A vacinação de rotina, o Dia Nacional da Vacinação, as campanhas periódicas e o sistema de vigilância são estratégias direcionadas do PNI ao enfrentamento de doenças imunopreveníveis(5).

A manutenção das altas coberturas nos padrões de números estimados e a homogeneidade proporcionam a efetividade das vacinas no âmbito individual e coletivo, assim como constituem-se um bom indicador de saúde pública, sendo capaz de superar o hiato social criado, muitas vezes, pelo próprio sistema de saúde ${ }^{(6)}$.

Desde a década de 90, o comportamento das coberturas vacinais no Brasil é positivo, refletido pela aceitação da população à vacinação e pelo êxito do PNI. No entanto, é inegável o fortalecimento do movimento antivacina, o qual contribui para a queda das coberturas vacinais e favorece a reintrodução de doenças imuproveníveis já em eliminação ${ }^{(7-9)}$. Mesmo ainda tímido no Brasil, esse movimento diminui a importância da imunização, fazendo com que se propaguem informações negativas (principalmente nas redes sociais) a respeito dessa temática e com que a população hesite em vacinar as crianças ${ }^{(8)}$. 
O Ministério da Saúde (MS), em 2010, realizou um estudo nacional com a proposta metodológica de monitoramento, análise e avaliação das coberturas vacinais, identificando os riscos de transmissão de doenças imunopreveníveis, com atualização dessa proposta no ano de 2016 com os indicadores que refletem a cobertura vacinal, e realizando a estratificação de risco de transmissão de doenças dos municípios ${ }^{(5,10)}$.

Com o atual cenário de ressurgimento de doenças imunopreveníveis, o movimento antivacina e o abandono dos esquemas multidoses pela população induzem a comportamentos e atitudes que potencializam o risco de transmissão dessas doenças, tanto no âmbito individual quanto nas redes sociais e comunitárias desse indivíduo ${ }^{(11)}$.

Nesse contexto, o estudo possibilitou descrever os indicadores de cobertura vacinal e o risco de transmissão de doenças imunopreveniveis.

\section{MÉTODOS}

Trata-se de um estudo ecológico descritivo que tem como unidade de análise a $1^{\text {a }}$ Região de Saúde do estado de Pernambuco ( $\left.1^{\mathrm{a}} \mathrm{RS} / \mathrm{PE}\right)$, composta por dezenove municípios mais o distrito estadual de Fernando de Noronha, como exposto na Figura 1. A escolha da região considerou se tratar da mais populosa do estado e possuir um polo de saúde de tecnologias variadas (Atenção Primária; Atenção Ambulatorial e Hospitalar; Urgência e Emergência; Atenção Psicossocial e Vigilância em Saúde) e ser uma região de expressiva migração, representando um desafio para a saúde pública local no que se refere ao controle e acesso aos dados demográficos e epidemiológicos desses indivíduos ${ }^{(12-14)}$.

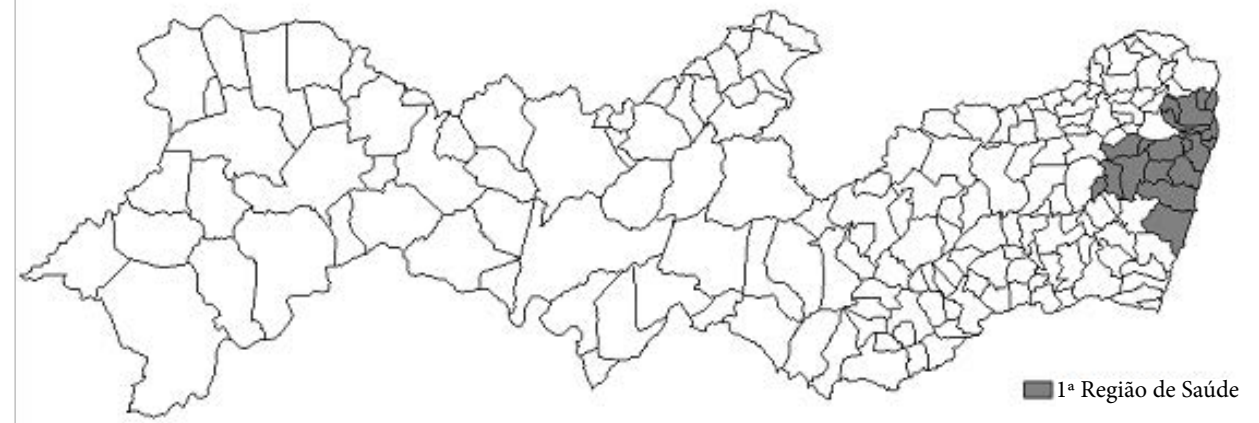

Figura 1 - Localização geográfica da 1ª Região de Saúde do Estado de Pernambuco, 2017.

Fonte: Plano Diretor de Regionalização/Secretaria Estadual de Saúde de Pernambuco-SES/PE, 2011(13).

Obtiveram-se as informações por meio de dados secundários provenientes do Sistema de Informação do Programa Nacional de Imunizações (SI-PNI) do estado de Pernambuco e do DATASUS (http://datasus.saude. gov.br/). Padronizaram-se as informações obtidas conforme o objetivo da pesquisa e os critérios de elegibilidade, seguindo o cálculo das variáveis para posterior análise descritiva a partir da distribuição de frequências absolutas, relativas e médias. Escolheu-se o ano de 2017 por ser o último ano com informações completas e a entrada de dados encerrada no site do DATASUS ${ }^{(15)}$.

Incluíram-se as vacinas preconizadas para crianças menores de dois anos, conforme calendário de 2018: pentavalente (três doses), poliomielite injetável (três doses), pneumocócica 10 (duas doses), rotavírus humano (duas doses), meningocócica $C$ (duas doses), tríplice viral, tetra viral e hepatite $A^{(16)}$.

Considerando a mudança de paradigma referente ao processo de nascimento, em que a autonomia e protagonismo da mulher perderam lugar para as técnicas obstétricas e hospitalização, excluíram-se as vacinas BCG (Bacilo Calmette-Guérin) e hepatite $B$ no estudo ${ }^{(17)}$. Estas são preconizadas ao nascer e, como muitos municípios não possuem assistência ao parto existe, um deslocamento intermunicipal das gestantes. Esse fenômeno pode interferir no mascaramento das reais coberturas para essas vacinas nos municípios ${ }^{(18)}$.

Também não se incluiu a vacina para febre amarela pelo fato do estado de Pernambuco não ser uma área de recomendação para essa vacina, assim como os reforços vacinais das vacinas analisadas, visto que, para a análise de suscetíveis, é utilizado o esquema básico, e não as doses de reforço ${ }^{(19)}$.

O risco de transmissão de doenças imunopreveníveis é a variável dependente descrita no estudo. Utilizou-se das seguintes variáveis independentes: cobertura vacinal $(C V)$, representando o percentual de vacinados na populaçãoalvo para cada vacina; a taxa de abandono (TA), que consiste em um indicador aplicado aos imunobiológicos com esquema multidoses e representa a adesão do usuário ao sistema de vacinação ${ }^{(13)}$; e a homogeneidade da cobertura vacinal $(\mathrm{HCV})$ entre vacinas, que medem a proporção das vacinas dentro de um contexto geográfico que atinge as coberturas adequadas e elevadas ${ }^{(20)}$. 
Para a CV, utilizaram-se valores calculados pelo MS para cada município, e realizou-se o cálculo da média da $\mathrm{CV}$ da regional por meio dos valores dos municípios. As metas vacinais consistem em $90 \%$ para rotavírus humano e 95\% para pentavalente, poliomielite, pneumocócica 10, meningocócica C (conjugada), tríplice viral, tetra viral e hepatite A, sendo propostas três classificações de coberturas vacinais: baixa (<meta), adequada ( $\geq$ meta $a \leq 120 \%)$ e elevada (>120\%). Para a taxa de abandono, a seguinte estratificação: baixa $(<5 \%)$, média $(\geq 5 \%$ a $\leq 10 \%)$ e alta $(>10 \%)^{(13)}$.

Para o cálculo da HCV, contabilizaram-se, para cada município, as vacinas que apresentaram CV adequadas e elevadas, dividindo pelo número de vacinas totais analisadas e multiplicando o resultado por 100. A TA considerou a diferença entre o número de primeiras doses e o número de últimas doses dividindo pelo número de primeiras doses e multiplicando o resultado por $100^{(13)}$.

De acordo com a Resolução CIB/PE n. ${ }^{0} 3.013$ de 08 de junho de 2017, que homologa diretrizes, objetivos, indicadores e metas para o estado de Pernambuco, o indicador da homogeneidade da cobertura vacinal entre vacinas para crianças menores de dois anos deve ser alcançada no mínimo $75 \%{ }^{(21)}$. Dessa forma, adaptou-se a classificação da metodologia utilizada pelo MS para esse indicador, visto que o estado de Pernambuco adota a proporção de $75 \%$ dessa resolução ${ }^{(21)}$ : baixa ( $\left.<75 \%\right)$ e adequada ( $\left.\geq 75 \%\right)$.

Não se incluiu na análise descritiva do risco o porte populacional dos municípios devido ao fato do Instituto Brasileiro de Geografia e Estatística (IBGE) utilizar, atualmente, estimativas populacionais, impossibilitando a fidedignidade desse dado para cada município ${ }^{(22)}$.

A estratificação do risco deu-se pelas seguintes categorias: risco muito alto quando a $\mathrm{HCV}$ for $<75 \%$ e TA $\geq 10 \%$ ou quando os municípios apresentarem nenhum registro de vacinação; risco alto quando a $\mathrm{HCV}$ for $<75 \%$; risco médio quando a $\mathrm{HCV}$ for $\geq 75 \%$ a $<100 \%$ e CV abaixo da meta para poliomielite, tríplice viral, tetraviral ou pentavalente; risco baixo quando a $\mathrm{HCV}$ for $\geq 75 \%$ a $100 \%$ e CV adequada para poliomielite, tríplice viral e tetra viral; e risco muito baixo quando a $\mathrm{HCV}$ for igual a $100 \%{ }^{(13)}$.

Utilizou-se os programas Excel (Microsoft Excel), versão 2013, e TabWin (Ministério da Saúde), versão 4.15, para realizar a estruturação do banco e análise dos dados. O estudo atendeu às considerações éticas propostas pela Resolução n. ${ }^{\circ} 466$ do Conselho Nacional de Saúde (CNS), de 12 de dezembro de 2012, sendo submetido ao Comitê de Ética em Pesquisa e aprovado com Parecer n. ${ }^{\circ}$ 3.075.787.

\section{RESULTADOS}

As vacinas da tríplice viral $(114,7 \%)$, pneumocócica $(102,7 \%)$, poliomielite $(99,5 \%)$, pentavalente $(99,4 \%)$ e hepatite $\mathrm{A}(96,8 \%)$ apresentaram média de CV adequadas na regional. No entanto, as vacinas da tetra viral $(79,6 \%)$, rotavírus $(85,1 \%)$ e meningocócica C $(94,6 \%)$ apresentaram médias abaixo da meta estabelecida na regional, refletindo o maior percentual de municípios com CV muito baixa e baixa, conforme exposto na Figura 2.

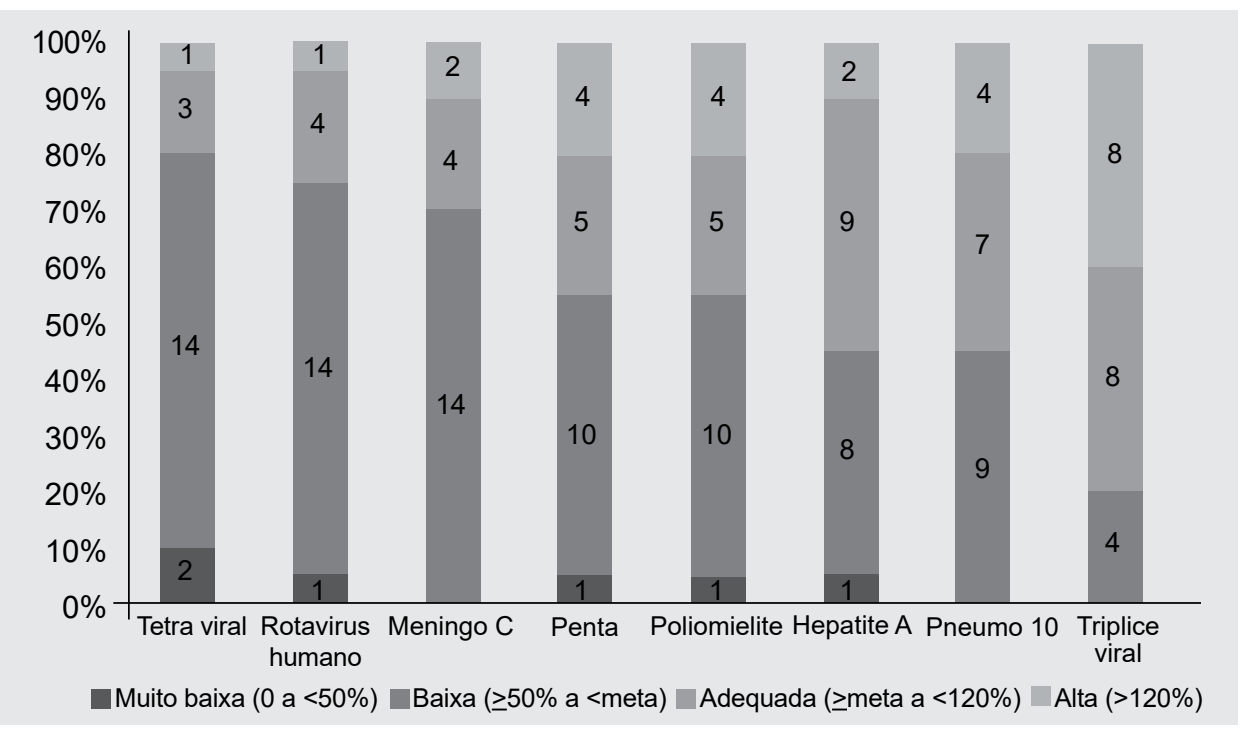

Figura 2 - Distribuição dos municípios (n e \%) conforme classificação da cobertura vacinal de oito vacinas na $1^{\text {a }}$ Região de Saúde do estado de Pernambuco, 2017.

Fonte: SIPNI: Sistema de Informação do Programa Nacional de Imunização; DATASUS: Departamento de Informática do Sistema Único de Saúde 
Fernando de Noronha e llha de Itamaracá atingiram CV adequada e elevada, respectivamente, em todas as vacinas. $\mathrm{Na}$ análise descritiva da HCV entre vacinas, $25 \%(n=5)$ dos municípios atingiram a meta de $75 \%$ preconizada pela Resolução CIB/PE n. ${ }^{0} 3.013$ de 08 de junho de $2017^{(21)}$, conforme consta na Figura 3.

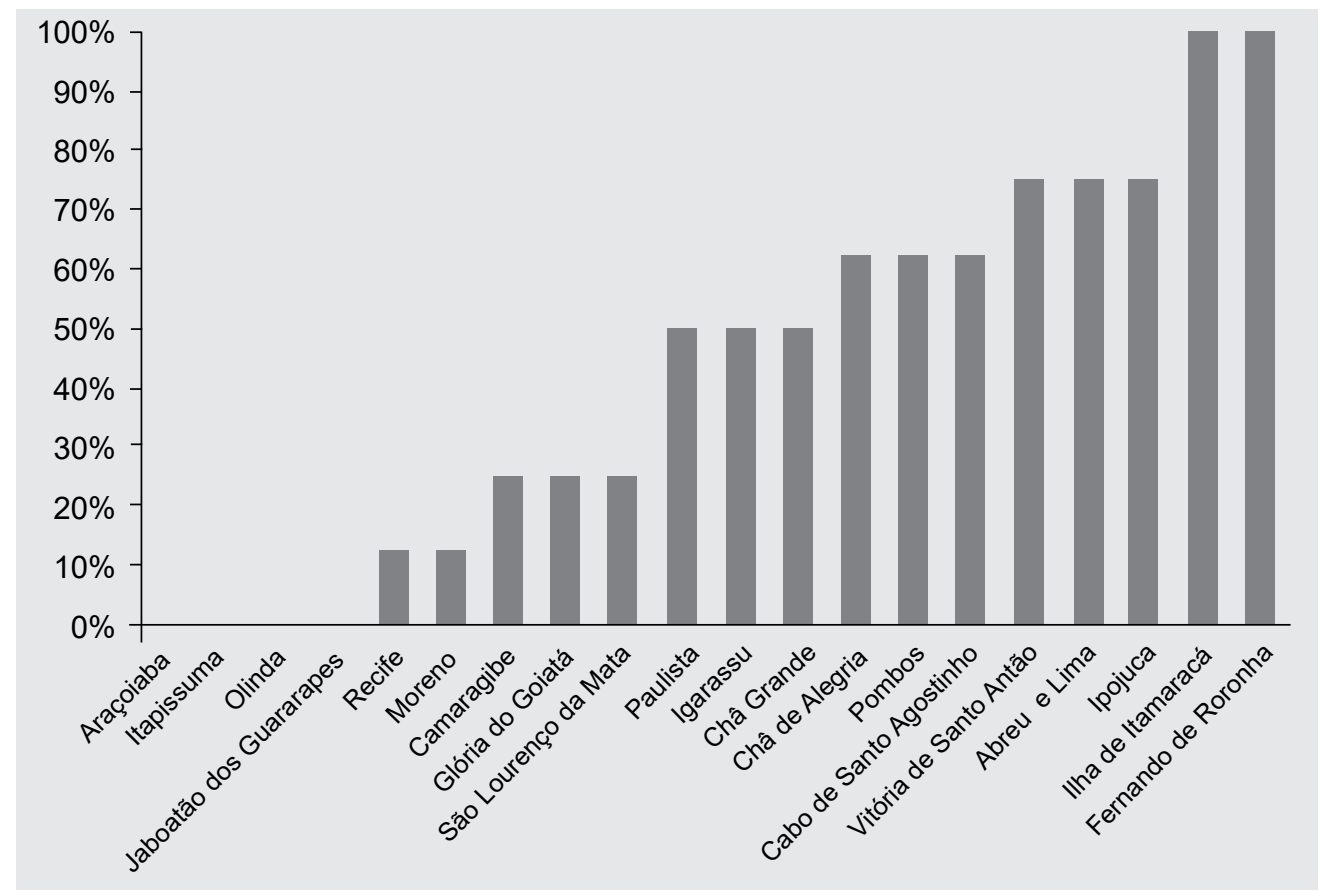

Figura 3 - Homogeneidade da cobertura vacinal entre vacinas na $1^{\text {a }}$ Região de Saúde do estado de Pernambuco, 2017.

Fonte: SIPNI: Sistema de Informação do Programa Nacional de Imunização; DATASUS: Departamento de Informática do Sistema Único de Saúde

A TA da regional apresentou percentual de 5,34\%, sendo considerada, conforme parâmetros do MS, como TA média. Os municípios de Glória do Goitá $(16,21 \%)$, Camaragibe $(13,55 \%)$ e Moreno $(11,83 \%)$ apresentaram as maiores médias de TA. Além disso, 45\% dos municípios apresentaram TA média e $40 \%$, TA baixa, sendo o distrito de Fernando de Noronha a menor média de TA da regional.

$\mathrm{Na} 1{ }^{\mathrm{a}} \mathrm{RS} / \mathrm{PE}$ a meningocócica $\mathrm{C}$ apresentou a maior proporção (70\%) de municípios com baixa taxa de abandono nos municípios em contraste com a vacina rotavírus (20\%), conforme exposto na Figura 4.

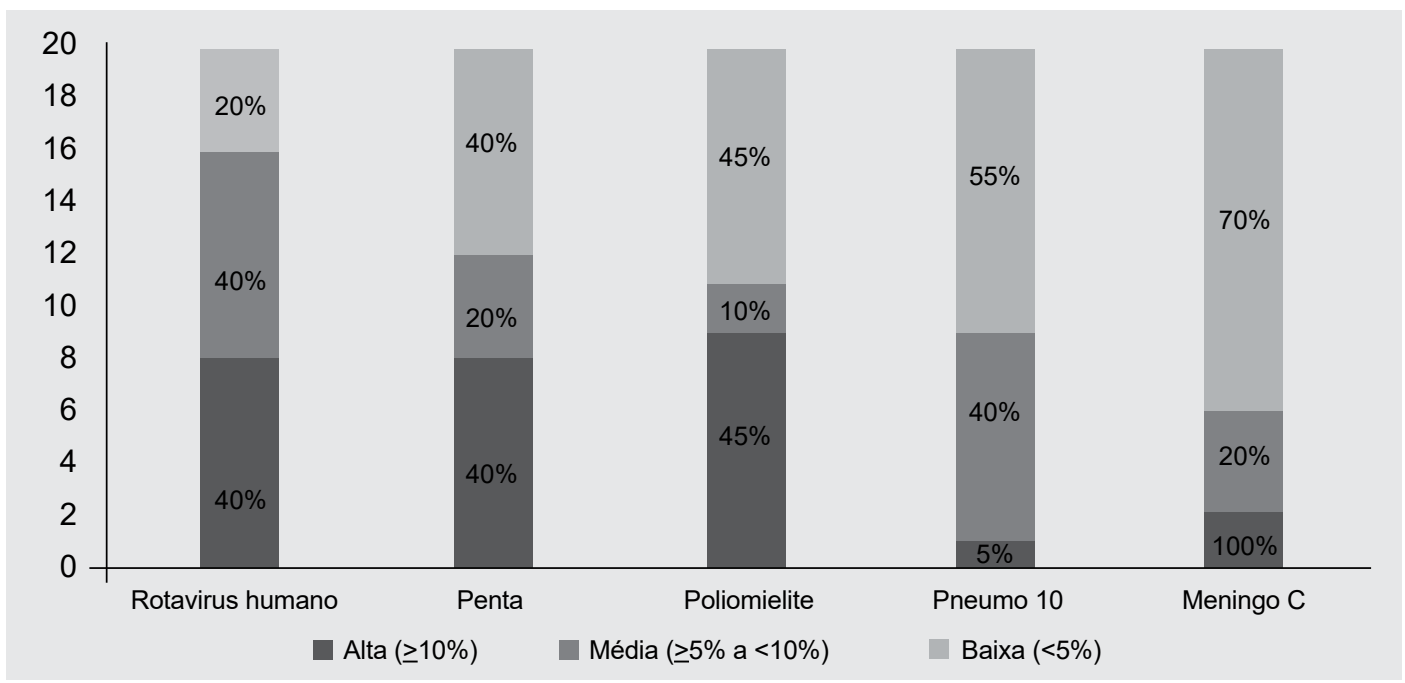

Figura 4 - Distribuição dos municípios ( $\mathrm{n}$ e \%) da $1^{\text {a }}$ Região de Saúde segundo taxa de abandono de cinco vacinas. Pernambuco, 2017.

Fonte: SIPNI: Sistema de Informação do Programa Nacional de Imunização; DATASUS: Departamento de Informática do Sistema Único de Saúde 
Por meio das variáveis independentes, categorizou-se o risco de transmissão de doenças imunopreveníveis para cada município, conforme consta na Figura 5.

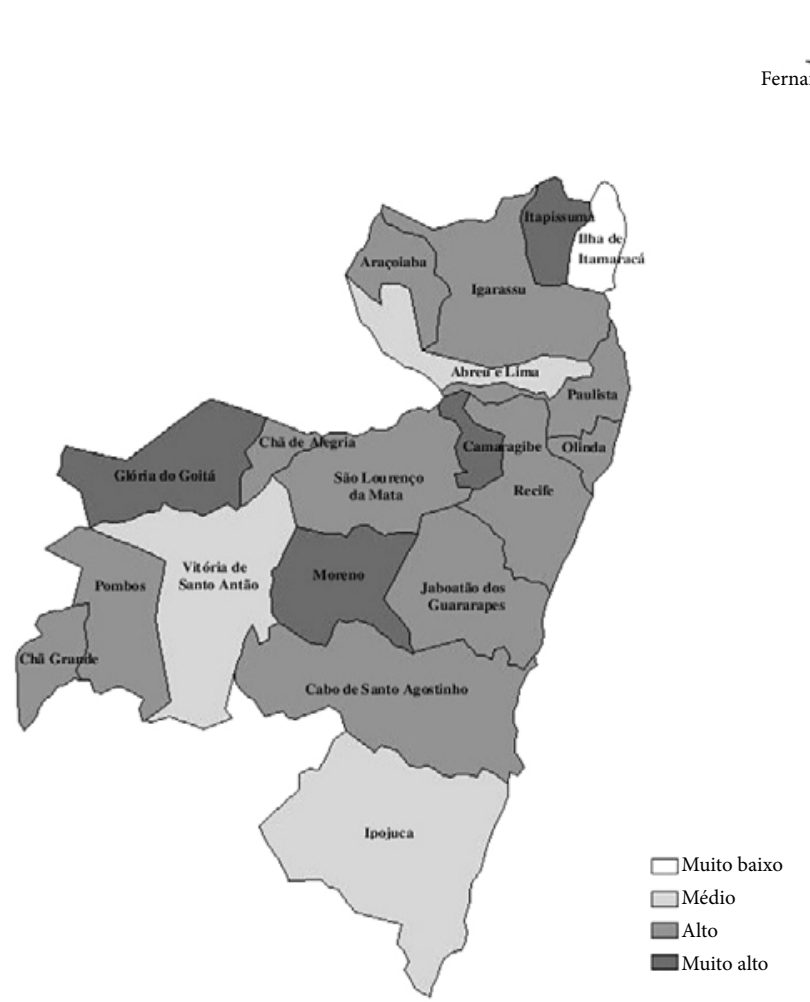

Figura 5 - Risco de transmissão de doenças imunopreveníveis nos municípios da $1^{\text {a }}$ Região de Saúde do estado de Pernambuco, 2017.

Fonte: TabWin versão 4.15

\section{DISCUSSÃO}

Os resultados encontrados no presente estudo ratificam a assertiva de que o PNI ainda apresenta desafios importantes, principalmente locais, no enfrentamento às doenças imunopreveníveis. As médias da CV na $1^{\text {a }} \mathrm{RS} /$ PE apresentaram valores baixos para algumas vacinas, em especial para a tetra viral; a qual está no Calendário Nacional de Imunização desde 2013 no intuito de atenuar as complicações, casos graves e óbitos por varicela, além de prevenir contra sarampo, rubéola e caxumba ${ }^{(23)}$.

Um estudo realizado no estado do Ceará evidenciou que alguns de seus municípios, no ano de 2015, também apresentaram baixa cobertura para a tríplice viral (sarampo, rubéola e caxumba) e apresentaram casos confirmados de sarampo ${ }^{(24)}$. Há algumas justificativas para o surgimento desses surtos, as quais se referem, justamente, à importação de casos, à alta transmissibilidade dessas doenças e à falta de homogeneidade das coberturas vacinais, fazendo com que uma parcela da população fique suscetível(25).

Não só no Brasil, observa-se que ainda existem países endêmicos para as doenças que a vacina tetra viral protege (sarampo, rubéola, caxumba e varicela). Na Europa, no ano de 2017, a Itália e a Romênia lideraram os casos de sarampo. Além disso, a Itália e a Áustria lideram os casos positivos para rubéola, fazendo com que as autoridades sanitárias dos países que recebem essas importações fiquem alerta às suas coberturas vacinais e ao risco de circulação dessas doenças ${ }^{(26)}$.

Em contraste com o resultado do presente estudo referente à cobertura da tetra viral, Cuba, desde a implantação do Programa de Imunização, em 1962, (quando as taxas de morbimortalidade eram elevadas para as doenças imunopreveníveis), tem melhorado seus indicadores vacinais, como no ano de 2016 , em que as coberturas de sarampo e rubéola alcançaram $100 \%$ e as taxas de incidência e mortalidade encontraram-se zeradas ${ }^{(27)}$.

Em relação à homogeneidade na $1^{\text {a }} \mathrm{RS} / \mathrm{PE}$, constatou-se que poucos municípios apresentaram suas $\mathrm{CV}$ adequadas e elevadas para todas as vacinas analisadas. Portanto, há a necessidade de estratégias de imunização e vigilância nos municípios que apresentaram CV baixas, com o objetivo de evitar um quadro epidemiológico desfavorável(28). Esse indicador é comumente utilizado no Brasil para análise do alcance das metas de cobertura das vacinas dentro de um contexto geográfico ${ }^{(13)}$. 
Um aspecto importante que está atrelado às baixas coberturas vacinais é a desigualdade geográfica referente à distribuição dos imunobiológicos, como mostra os dados de um estudo realizado em 49 países africanos por meio de inquéritos. Esse estudo permitiu visualizar os locais mais vulneráveis de recursos e traçar estratégias de distribuição equitativa, no intuito de garantir melhores resultados de saúde para as crianças africanas ${ }^{(29)}$.

Algumas vacinas se destacaram na proporção de abandono no presente estudo. Dentre elas, estão: a rotavírus, pentavalente, poliomielite, pneumocócica 10 e meningocócica C. Observa-se a temática da proporção de abandono vacinal no intuito de explorar quais fatores potencializam esse indicador ${ }^{(30)}$.

Em um estudo de coorte prospectivo, realizado em São Luís do Maranhão, identificou-se os fatores relacionados a esse indicador de proporção de abandono, tais como: baixa escolaridade materna; gravidez na adolescência e não planejada; busca tardia à assistência do pré-natal; aumento do número de irmãos da criança no domicílio; ausência de atendimento ambulatorial e/ou hospitalar; e indisponibilidade das vacinas nos serviços de saúde ${ }^{(30)}$.

Para compreender melhor os fatores envolvidos na proporção de abandono, outro estudo analisou prontuários eletrônicos de crianças menores de dois anos pertencentes a uma microárea do município do Rio de Janeiro, evidenciando que a pneumocócica 10 e a meningocócica $C$ apresentaram maior proporção de abandono ${ }^{(31)}$, dado inverso ao resultado obtido no presente estudo.

Um estudo apontou que o processo de vacinação caracteriza-se como um fenômeno que também engloba fatores sociais, identificando outras barreiras de acesso aos imunobiológicos, como as reações pós-vacinação (dor e febre) e o desemprego dos cuidadores ${ }^{(32)}$.

No presente estudo, a vacina rotavírus apresentou maior proporção de abandono. A causa de diarreia por rotavírus ainda é uma problemática atual para a saúde pública, acarretando problemas, principalmente, aos menores de cinco anos em todo o mundo ${ }^{(33)}$. Nessa perspectiva, é necessário esforços nas estratégias vacinais para atenuar a proporção de abandono na regional estudada para essa vacina, considerando o impacto que a doença tem na saúde infantil(33).

Dados da Organização Mundial de Saúde referentes à pentavalente, segunda maior em proporção de abandono no estudo, que é uma vacina conjugada contra difteria, tétano, coqueluche, hepatite B e cepas do Haemophilus influenzae do tipo b (Hib), indicam que 1 a cada 10 crianças no mundo não recebeu a primeira dose da DTP (difteria, tétano e coqueluche), e a cobertura mundial dessa vacina era de $86 \%$. A terceira dose dessa vacina é considerada como um indicador de avaliação de cobertura dos serviços assistenciais às crianças ${ }^{(34)}$.

Em especial a coqueluche, que é uma das doenças que a pentavalente previne, um estudo realizado em Minas Gerais evidenciou um aumento na sua incidência, de 2005 a 2014, em consequência de uma cobertura vacinal abaixo dos $90 \%$, sendo, portanto, abaixo da meta preconizada pelo MS, o que representa um alerta para possíveis surtos em crianças, visto que o contato se dá de forma direta(35).

Referente à difteria, o estado de Roraima, durante o período de 1989 a 2017, notificou cinco casos de difteria, todos na capital Boa Vista, fato decorrente da baixa cobertura vacinal e da falta de homogeneidade ${ }^{(36)}$. Em Pernambuco, somente no ano de 2015, foram confirmados onze casos de difteria, sendo distribuídos nos municípios de Chã Grande, Salgueiro, Recife e Jaboatão dos Guararapes ${ }^{(37)}$. Dessa forma, ratifica-se a importância de completar o esquema vacinal nas crianças, que são mais vulneráveis a casos graves.

A saúde da criança configura-se como uma estratégia prioritária na agenda da saúde. A promoção integral à sua saúde tem como principal meta a diminuição da morbimortalidade, que ainda afeta esse público. Desse modo, as práticas de imunização, com a garantia de altas coberturas, a diminuição da taxa de abandono e, consequentemente, a diminuição do risco de transmissão, estão intimamente associadas ao êxito dessa meta, visto que se configura como um elemento essencial no crescimento e desenvolvimento na infância ${ }^{(38)}$.

Um ponto importante a ser discutido refere-se à educação permanente dos profissionais que lidam com as atividades de imunização, já que são considerados pela população como fonte principal de informação e, assim, interferir nas coberturas vacinais e no processo saúde-doença das crianças ${ }^{(2,39)}$. Um estudo apontou que a maioria dos profissionais da atenção básica não soube responder adequadamente sobre quais vacinas devem ser administradas nas respectivas idades, evidenciando que o processo de capacitação seja contínuo ${ }^{(39)}$.

A dependência completa dos adultos é uma característica que faz do processo saúde-doença das crianças prioridade, tanto para seus responsáveis e cuidadores diretos quanto para as políticas voltadas para esse público. Dessa forma, as ações e estratégias devem ser de cunho intra e intersetorial, perpassando por ações de proteção e promoção da saúde, no intuito de atenuar os riscos e vulnerabilidades e garantir um desenvolvimento harmonioso e saudável(40).

A análise conjunta dos indicadores vacinais permitiu uma maior compreensão do real cenário vacinal das localidades, requerendo avaliações e ações estratégicas constantes para mudança do perfil epidemiológico do risco( ${ }^{(13)}$ 
dos municípios da $1^{\text {a }}$ RS/PE. Dessa forma, requer esforços conjuntos (pelos diversos setores sociais envolvidos) no planejamento e incorporação de medidas eficazes e, principalmente, universais ${ }^{(35)}$.

\section{CONCLUSÃO}

Nos municípios analisados há um enquadramento nas categorias de risco muito alto e alto, além de baixos indicadores de cobertura vacinal, evidenciando que há uma relação inversamente proporcional entre o risco e os indicadores.

\section{CONFLITOS DE INTERESSE}

Os autores declaram não existirem conflito de interesses.

\section{CONTRIBUIÇÕES}

Aline Beatriz dos Santos Silva, Ana Catarina de Melo Araújo, Michelle Caroline da Silva Santos e Maria Sandra Andrade contribuíram com a elaboração e delineamento do estudo; a aquisição, análise e interpretação dos dados; e a redação do manuscrito. Rafael Mota Mendonça contribuiu com a aquisição, análise e interpretação dos dados.

\section{REFERÊNCIAS}

1. Organização Mundial da Saúde. Plan de acción mundial sobre vacunas 2011-2020 [Internet]. Genebra: OMS; 2013 [acesso em 2019 Jan 18]. Disponível em: https://www.who.int/immunization/global_vaccine_action_ plan/DoV_GVAP_2012_2020/es/

2. Assad SGB, Corvino MPF, Santos SCP, Cortez EA, Souza FL. Educação Permanente em Saúde e atividades de vacinação: revisão integrativa. Rev Enferm UFPE [Internet]. 2017 [acesso em 2019 Jul 02];11(Supl.1):41021. Disponível em: https://periodicos.ufpe.br/revistas/revistaenfermagem/article/view/11922

3. Lima AA, Pinto ES. O contexto histórico da implantação do Programa Nacional de Imunização (PNI) e sua importância para o Sistema Único de Saúde (SUS). Scire Salutis [Internet]. 2017 [acesso em 2019 Jan 20];(1):53-62. Disponível em: https://sustenere.co/journals/index.php/sciresalutis/article/view/SPC22369600.2017.001.0005

4. Ministério da Saúde (BR). Secretaria de Vigilância em Saúde. Departamento de Vigilância Epidemiológica. Programa Nacional de Imunizações (PNI): 40 anos [Internet]. 2013 [acesso em 2019 Jan 22]. Disponível em: http://bvsms.saude.gov.br/bvs/publicacoes/programa_nacional_imunizacoes_pni40.pdf

5. Teixeira AMS, Rocha CMV. Vigilância das coberturas de vacinação: uma metodologia para detecção e intervenção em situações de risco. Epidemiol Serv Saúde [Internet]. 2010 [acesso em 2019 Jan 23];19(3):217-26. Disponível em: http://scielo.iec.gov.br/scielo.php?script=sci_arttext\&pid $=$ S1679-49742010000300004

6. Luhm KR, Cardoso MRA, Waldman EA. Cobertura vacinal em menores de dois anos a partir do registro informatizado de imunização em Curitiba, PR. Rev Saúde Pública [Internet]. 2011 [acesso em 2019 Jan 26];45(1):90-8. Disponível em: http://www.scielo.br/scielo.php?script=sci_arttext\&pid =S0034-89102011000100010

7. Sato APS. Qual a importância da hesitação vacinal na queda das coberturas vacinais no Brasil? Rev Saúde Pública [Internet]. 2018 [acesso em 2019 Jan 26];52(96):1-9. Disponível em: http://www.rsp.fsp.usp.br/artigo/ qual-a-importância-da-hesitacao-vacinal-na-queda-das-coberturas-vacinais-no-brasil/

8. MacDonald NE. Vaccine hesitancy: definition, scope and determinants. Vaccine [Internet]. 2015 [acesso em 2019 Jul 05];33(34):4161:64. Disponível em: https://www.sciencedirect.com/science/article/pii/ S0264410X15005009?via\%3Dihub

9. Ministério da Saúde (BR). Sarampo: situação epidemiológica [Internet]. Brasília: Ministério da Saúde; 2018 [acesso em 2019 Fev 18]. Disponível em: http://www.saude.gov.br/saude-de-a-z/sarampo-situacaoepidemiologica 
10. Braz RM, Domingues CMAS, Teixeira AMS, Luna EJA. Classificação de risco de transmissão de doenças imunopreveníveis a partir de indicadores de coberturas vacinais nos municípios brasileiros. Epidemiol Serv Saúde [Internet]. 2016 [acesso em 2019 Fev 19];25(4):745-54. Disponível em: http://www.scielo.br/scielo. php?pid=S2237-96222016000400745\&script=sci_abstract\&tlng=pt

11. Mizuta AH, Succi GM, Montalli VAM, Succi RCM. Percepções acerca da importância das vacinas e da recusa vacinal numa escola de medicina. Rev Paul Pediatr [Internet]. 2019 [acesso em 2019 Jul 03];37(1):34-40. Disponível em: http://www.scielo.br/scielo.php?script=sci_abstract\&pid=S0103-05822019000100034\&lng=en \&nrm=iso\&tlng $=p t$

12. Dias S, Gonçalves A. Migração e Saúde. Rev Migrações [Internet]. 2007 [acesso em 2019 Jan 21];(1):15-26. Disponível em: http://www.uc.pt/fluc/gigs/GeoHealthS/doc_apoio/migracoes_e_saude.pdf

13. Secretaria de Saúde do Estado de Pernambuco (BR). Secretaria Executiva de Regulação em Saúde. Plano diretor de regionalização [internet]. Recife: SES/PE; 2011 [acesso em 2018 Dez 20]. Disponível em: http:// ead.saude.pe.gov.br/mod/resource/view.php?id=707

14. Brasil. Decreto $n^{\circ} 7.508$, de 28 de junho de 2011. Regulamenta a Lei $n^{\circ} 8.080$, de 19 de setembro de 1990 , para dispor sobre a organização do Sistema Único de Saúde - SUS, o planejamento da saúde, a assistência à saúde e a articulação interfederativa, e dá outras providências. Diário Oficial da União, 29 de junho de 2011.

15. Ministério da Saúde (BR). Departamento de Informática do SUS-DATASUS. Informações de saúde (TABNET): Assistência à saúde [Internet]. 2017 [acesso em 2019 Mar 06]. Disponível em: http://www2. datasus.gov.br/DATASUS/Estatisticas_TABNET_2017/Mtab2017.htm

16. Ministério da Saúde (BR). Calendário Nacional de Vacinação [Internet]. 2019 [acesso em 2019 Abr 20]. Disponível em: http://www.saude.gov.br/saude-de-a-z/vacinacao/calendario-vacinacao

17. Velho MB, Santos EKA, Collaço VS. Parto normal e cesárea: representações sociais de mulheres que os vivenciaram. Rev Bras Enferm [Internet]. 2014 [acesso em 2019 Jan 20];67(2):282-9. Disponível em: http:// www.scielo.br/scielo.php?pid=S0034-71672014000200282\&script=sci_abstract\&tlng=pt

18. Sousa LMO, Araújo ED, Miranda JGV. Caracterização do acesso à assistência ao parto normal na Bahia, Brasil, a partir da teoria dos grafos. Cad Saúde Pública [Internet]. 2017 [acesso em 2019 Jan 21];33(12):1-12. Disponivel em: http://www.scielo.br/scielo.php?pid=S0102-311X2017001205011\&script=sci_abstract\&tlng=pt

19. Ministério da Saúde (BR). Coordenação Geral do Programa Nacional de Imunização. Nota Informativa No 118-SEI/2017-CGPNI/DEVIT/SVS/MS. Atualização das áreas de recomendação para vacinação contra febre amarela [Internet]. 2017 [acesso em 2019 Fev 24]. Disponível em: http://portalarquivos2.saude.gov.br/images/ pdf/2017/novembro/30/SEI_MS-1521369-Nota-Informativa-118-recomendacao-vacina-fa.pdf

20. Domingues CMA, Teixeira AMS, Carvalho SMD. National Immunization Program: vaccination, compliance and pharmacovigilance. Rev Inst Med Trop [Internet]. 2012 [acesso em 2019 Jan 20];54(supl. 18):22-7. Disponível em: http://www.scielo.br/scielo.php?script=sci_arttext\&pid=S0036-46652012000700009

21. Secretaria de Saúde do Estado de Pernambuco. Resolução CIB/PE n 3.013 de 08 de junho de 2017. Homologa Diretrizes, Objetivos, Indicadores e Metas Pactuados no ano de 2017 para o Estado de Pernambuco. Diário Oficial do Estado, Poder Executivo, ano XCIV.

22. Instituto Brasileiro de Geografia e Estatística. Pesquisa Nacional de Saúde (PNS): ciclos de vida [Internet]. Rio de Janeiro: IBGE; 2015 [acesso em 2019 Mar 10]. Disponível em: https://sidra.ibge.gov.br/pesquisa/pns

23. Ministério da Saúde (BR). Secretaria de Vigilância em Saúde. Departamento de Vigilância Epidemiológica. Coordenação-Geral do Programa de Imunizações. Informe Técnico de Introdução da vacina tetra viral [Internet]. 2013 [acesso em 2019 Fev 2]. Disponível em: http://www.sopape.com.br/data/conteudo/arquivos/ informe_tecnico_introducao_vacina_tetraviral.pdf

24. Moura ADA, Carneiro AKB, Braga AVL, Bastos ECSA, Canto SVE, Figueiredo TWS, et al. Estratégias e resultados da vacinação no enfrentamento da epidemia de sarampo no estado do Ceará, 2013-2015. Epidemiol Serv Saúde [Internet]. 2018 [acesso em 2019 Fev 05];27(1):1-8. Disponível em: http://www.scielo. br/scielo.php?pid=S2237-96222018000100600\&script=sci_abstract\&tIng=pt 
25. Ribeiro C, Menezes C, Lamas C. Sarampo: achados epidemiológicos recentes e implicações para a prática clínica. Almanaque Multidiscip Pesqui [Internet]. 2015 [acesso em 2019 Fev 05];1(2):4-16. Disponível em: http://publicacoes.unigranrio.edu.br/index.php/amp/article/view/3343/1568

26. European Center for Disease Prevention and Control. Monthly measles and rubella monitoring report [Internet]. 2017 [acesso em 2019 Fev 05]. Disponível em: https://ecdc.europa.eu/en/publications-data/ monthly-measles-and-rubella-monitoring-report-december-2018

27. Ambrón LL, Torres LIE, Carreras AP, Santana BMG, Sardiña MAG, Aguirre SR, et al. Experiencia cubana em inmunización, 1962-2016. Rev Panam Salud Pública [Internet]. 2018 [acesso em 2019 Fev 06];42:1-9. Disponível em: http://iris.paho.org/xmlui/handle/123456789/34905

28. Doherty M, Buchy P, Standaert B, Giaquinto C, Prado D. Vaccine impact: Benefits for human health. Vaccine [Internet]. 2016 [acesso em 2019 Fev 07];34:6707-14. Disponível em: https://www.sciencedirect.com/science/ article/pii/S0264410X16309434?via\%3Dihub

29. Mosser JF, Gagne-Maynard W, Rao PC, Osgood-Zimmerman A, Fullman N, Graetz N, et al. Mapping diphtheria-pertussis-tetanus vaccine coverage in Africa, 2000-2016: a spacial and temporal modelling study. Lancet [Internet]. 2019 [acesso em 2019 Ago 05];393:1843-55. Disponível em: https://www.thelancet.com/ journals/lancet/article/PIIS0140-6736(19)30226-0/fulltext

30. Silva FS, Barbosa YC, Batalha MA, Ribeiro MRC, Simões VMF, Branco MRFC, et al. Incompletude vacinal infantil de vacinas novas e antigas e fatores associados: coorte de nascimento BRISA, São Luís, Maranhão, Nordeste do Brasil. Cad Saúde Pública [Internet]. 2018 [acesso em 2019 Fev 07];34(3):1-21. Disponível em: http://www.scielo.br/scielo.php?script=sci_abstract\&pid=S0102-311X2018000305012\&lng=en\&nrm=iso\&tlng= $\mathrm{pt}$

31. Filgueiras RS, Schaustz MLR, Filgueiras PS, Fonseca SC. Cobertura vacinal em crianças de até dois anos: o prontuário eletrônico no município do Rio de Janeiro. Acad Rev Cient Saúde [Internet]. 2018 [acesso em 2019 Fev 07];3(1):39-45. Disponível em: https://smsrio.org/revista/index.php/reva/article/view/402

32. Escobar-Díaz F, Osorio-Merchán MB, De laHoz-Restrepo F. Motivos de no vacunación en menores de cinco años em cuatro ciudades colombianas. Rev Panam Salud Pública [Internet]. 2017 [acesso em $2019 \mathrm{Fev}$ 08];41:1-6. Disponível em: https://www.scielosp.org/article/rpsp/2017.v41/e123/

33. World Health Organization. Rotavirus vaccines WHO position paper - January 2013. Wkly Epidemiol Rec [Internet]. 2013 [acesso em 2019 Mar 08];88(5):49-64. Disponível em: http://www.who.int/wer/2013/wer8805. pdf?ua $=1$

34. World Health Organization. World health statistics 2018: monitoring health for the SDGs, sustainable development goals [Internet]. 2018 [acesso em 2019 Fev 18]. Disponível em: https://www.who.int/gho/ publications/world_health_statistics/2018/en/

35. Castro JM, Cabrera GPB. Avaliação da cobertura vacinal em menores de cinco em um Município do Leste de Minas Gerais. Rev Ensaios Cienc Cienc Biol Agrar Saúde. 2017;21(1):36-41.

36. Benedetti MSG. Difteria em Roraima: análise epidemiológica no período de 1989 a 2017. Braz J Hea Rev [Internet]. 2019 [acesso em 2019 Fev 20];2(1):571-9. Disponível em: http://www.brjd.com.br/index.php/BJHR/ article/view/1136

37. Ministério da Saúde (BR). Sistema de Informação de Agravos de Notificação-SINAN. Difteria [Internet]. 2015 [acesso em 2019 Fev 19]. Disponível em: https://portalarquivos2.saude.gov.br/images/pdf/2018/marco/12/BRDif-Informe-2015.pdf

38. Damasceno SS, Nóbrega VM, Coutinho SED, Reichert APS, Toso BRGO, Collet N. Saúde da criança no Brasil: orientação da rede básica à Atenção Primária à Saúde. Cien Saúde Colet [Internet]. 2016 [acesso em 2019 Ago 05];21(9):2961-73. Disponível em: http://www.scielo.br/scielo.php?pid=S1413$81232016000902961 \&$ script $=$ sci_abstract\&tIng=pt

39. Souza IBJ, Lago EC, Araújo TME, Almeida CAPL, Tapety FI, Carvalho ML. Conhecimento de enfermeiros e médicos de uma microrregião do Nordeste brasileiro sobre a vacinação infantil. Nursing (São Paulo) [Internet]. 2018 [acesso em 2019 Ago 08];21(247):2498-2505. Disponível em: http://pesquisa.bvsalud.org/ portal/resource/pt/biblio-970888 
40. Ministério da Saúde (BR). Secretaria de Atenção à Saúde. Departamento de Ações Programáticas Estratégicas. Política Nacional de Atenção Integral à Saúde da Criança: orientações para implementação. [internet]. Brasília: Ministério da Saúde; 2018 [acesso em 2019 Fev 05]. Disponível em: http://www.saude. pr.gov.br/arquivos/File/Politica_Nacional_de_Atencao_Integral_a_Saude_da_Crianca_PNAISC.pdf

\section{Endereço para correspondência:}

Aline Beatriz dos Santos Silva

Universidade Federal de Pernambuco - UFPE

Programa de Pós-Graduação em Saúde Coletiva

Avenida Professor Moraes Rego, s/n - Hospital das Clínicas, Bloco E - $4^{\circ}$ andar

Bairro: Cidade Universitária

CEP: 50.670-901 - Recife - PE - Brasil

E-mail: alinebeatriz92@gmail.com

Como citar: Silva ABS, Araújo ACM, Santos MCS, Andrade MS, Mendonça RM. Indicadores de cobertura vacinal para classificação de risco de doenças imunopreveníveis. Rev Bras Promoç Saúde. 2019;32:9285. 